\title{
Constrains in Biofertilizer Development and Environmental Factors Influencing its Survival in Soil: A Review
}

\author{
R.S. Vidhya Ganesh, M. Nithish Kumar, J. Kavipriya, R. Krishnamoorthy
}

10.18805/ag.R-2348

\begin{abstract}
Bio-inoculants (Biofertilizer) are an agricultural input that helps to keep the environment clean. By definition biofertilizers are efficient strains of isolated microorganisms that help plants grow in a variety of ways, both directly and indirectly. Biological nitrogen fixation, phosphate solubilization, phosphate mobilisation, siderophore generation and phytohormone production are some of the direct methods. The majority of efficient bio-inoculants perform better in laboratory conditions but fail to achieve the same results in the field. Due to the poor performance of bio-inoculants in field conditions, biofertilizers are not widely accepted by the farming community. Soil $\mathrm{pH}$, temperature and chemical residues are considered as important abiotic stress. The key soil biotic elements are native microflora, predatory organisms and virus. Some bacteria are able to live despite the stress, but the total efficacy of the applied biofertilizer is diminished. Bio-inoculants must resist a variety of biotic and abiotic stresses in the soil, depending on the circumstances. We look at the obstacles that bio-inoculants confront in terms of survival and performance in the field.
\end{abstract}

Key words: Bio-inoculants, Biotic factor, Constrains, Quality control, Survival.

Despite the fact that grain production has doubled in the last four decades as a result of the widespread use of synthetic fertilisers and pesticides during the green revolution, this rate of increased agricultural output is unsustainable due to declining crop yields and the environmental impacts of modern agricultural practises. In many nations, improper agrochemical use is one of the most serious environmental challenges. In India, after the green revolution, the usage of synthetic chemicals in agriculture has skyrocketed, resulting in increased food production. On the other side, continued use of synthetic substances causes a slew of environmental problems, including harm to soil flora and wildlife as well as human health (Meena et al., 2020). Zhang et al. (2018) conducted a review that clearly established the impact of pesticide use on the ecosystem over the last 30 years. Readers can consult Meena et al. (2020) and Tudi et al. (2021) for further information on the negative influence of agrochemicals on environmental issues. The loss of soil microflora is a major consequence of chemical use in agriculture. When the soil's microbial population declines, soil fertility suffers and the soil becomes degraded (Basu et al., 2021; Palia et al., 2021).

Soil microflora can be promoted in a sustainable manner by reducing the use of agrochemicals and increasing the use of bio inputs. Bio-inoculants (biofertilizers) are one of the numerous bio inputs used in agriculture and are one of the most essential products that aid in soil fertility and plant growth. Bio-inoculants are agricultural amendments that increase soil and plant health by using helpful microorganisms. Bio-inoculants are developing as a viable alternative to synthetic agrochemicals in terms of reducing their negative environmental impact (Aruna and Jain, 2021; Basu et al., 2021). The microorganisms in biofertilizers deliver benefits to agricultural plants through a variety of direct and
Vanavarayar Institute of Agriculture, Manakkadavu, Pollachi-642 103, Tamil Nadu, India.

Corresponding Author: R. Krishnamoorthy, Department of Crop Management, Vanavarayar Institute of Agriculture, Manakkadavu, Pollachi-642 103, Tamil Nadu, India.

Email: moorthy.micro@gmail.com

How to cite this article: Ganesh, R.S.V., Kumar, M.N., Kavipriya, $\mathrm{J}$. and Krishnamoorthy, R. (2022). Constrains in Biofertilizer Development and Environmental Factors Influencing its Survival in Soil: A Review. Agricultural Reviews. DOI: 10.18805/ag.R-2348. Submitted: 11-08-2021 Accepted: 07-12-2021 Online: 21-01-2022

indirect ways. This could be in the areas of nitrogen fixation, phosphate solubilization, nutrient mobilisation, stress mitigation and plant growth promotion (PGP), or a combination of these features (Bhardwaj et al., 2014).

The use of an effective bio-inoculant that performs well in the lab and in greenhouse settings does not always result in the expected effects on plant development in the field. This review includes information on the parameters that influence bio-inoculant adaption and performance in farmers' fields (both biotic and abiotic factors), in addition constrains also discussed.

\section{Factors influencing bio-inoculants}

A thorough understanding of target soils and rhizospheres as habitats for imported microbes is required for the development of bio-inoculants that sustain beneficial microorganisms in the soil. The survival of imported bioinoculants in soil is influenced by a variety of biotic and abiotic variables, as shown in Fig 1 . The next sections go through the specifics of each aspect. 


\section{Soil temperature}

The temperature of the soil is determined by heat flow in the soil and heat exchanges between the soil and the atmosphere. The longevity of applied bio-inoculants in soil is influenced by temperature. Microbial activity is stronger when the soil temperature is between 15 and 30 degrees Celsius (Allison et al., 2010) and it is lowered as the soil temperature rises and falls. Solar radiation is the primary source of soil temperature, which is measured using a thermometer. Soil temperature fluctuates a lot and it varies seasonally, daily and even hourly depending on solar radiation. The majority of bio-inoculants used in the biofertilizer business operate better at ideal soil temperatures of $28^{\circ} \mathrm{C}$ to $35^{\circ} \mathrm{C}$, however due to global warming, soil temperature fluctuations are becoming a big challenge for bio-inoculants. The symbiosis between Bradyrhizobium japonicum and soybean is inhibited by temperatures near $15^{\circ} \mathrm{C}$ (Antoun and Prevost, 2005). Furthermore, at $15^{\circ} \mathrm{C}, B$. japonicum nod factor production and nodulation efficiency are impaired (Duzan et al., 2006). On the other side, it was discovered that raising the soil temperature above $40^{\circ} \mathrm{C}$ causes microbial cell death (Wu et al., 2010). Chen et al. (2002), on the other hand, reported identified and screened Rhizobium strains that tolerate $40^{\circ} \mathrm{C}$ and nodulate soybean crops. Some strains may have evolved resistance mechanisms that allow them to perform better at higher or lower temperatures. As a result, all bioinoculants must be chosen for their ability to survive and perform in a wide range of soil temperatures.

\section{Soil pH}

Rhizobium legume symbiosis is a well-studied and ancient symbiosis. Only adequate communication between Rhizobium bacteria and plant roots can develop this relationship. Changes in soil $\mathrm{pH}$, on the other hand, have a significant impact on signalling molecule synthesis, plant root attachment, nodule formation and soil longevity (Lin et al., 2012). Fig 2 depicts the $\mathrm{pH}$ effect on nodulation activity and nitrogen fixation process. Soil acidity has an impact on the nodulation process and nitrogen fixation, from rhizobia survival and multiplication in the soil to infection and nodulation and finally nitrogen fixation (Graham, 1992). Rhizobium spp. are less acid tolerant than Bradyrhizobium spp. Lin et al. (2012) found that when soil pH is decreased below 5.5, Bradyrhizobium japonicum nodulation in soybean is greatly influenced. Furthermore, the scientists provided genetic evidence that when soil $\mathrm{pH}$ is low, genes involved in forming a symbiotic interaction between soybean and rhizobium are down regulated. In contrast to this $\mathrm{pH}$, when compared to neutral $\mathrm{pH}$, Rhizobium tropici CIAT899 tolerance was shown to grow efficient nodules at a $\mathrm{pH}$ of 5.5 (Morón et al., 2005). Because the results of the preceding study show that some rhizobium stains operate better in neutral $\mathrm{pH}$ soil and others in acidic $\mathrm{pH}$ soil, bio-inoculants should be tested in a variety of soil $\mathrm{pH}$ levels before being formulated. Furthermore, appropriate strains must be selected for various soil conditions and this information must be clearly stated on the product label.

\section{Agrochemical residues in soil}

The number and quality of soil micro and macro flora are the most important factors in determining soil fertility. Traditional farming practises, on the other hand, have an impact on soil flora. Agrochemicals have affected soil biodiversity, agricultural sustainability and food safety, resulting in long-term detrimental effects for nutritional security and human health (Meena et al., 2020). Table 1 shows a list of key agrochemicals and their impact on bio-

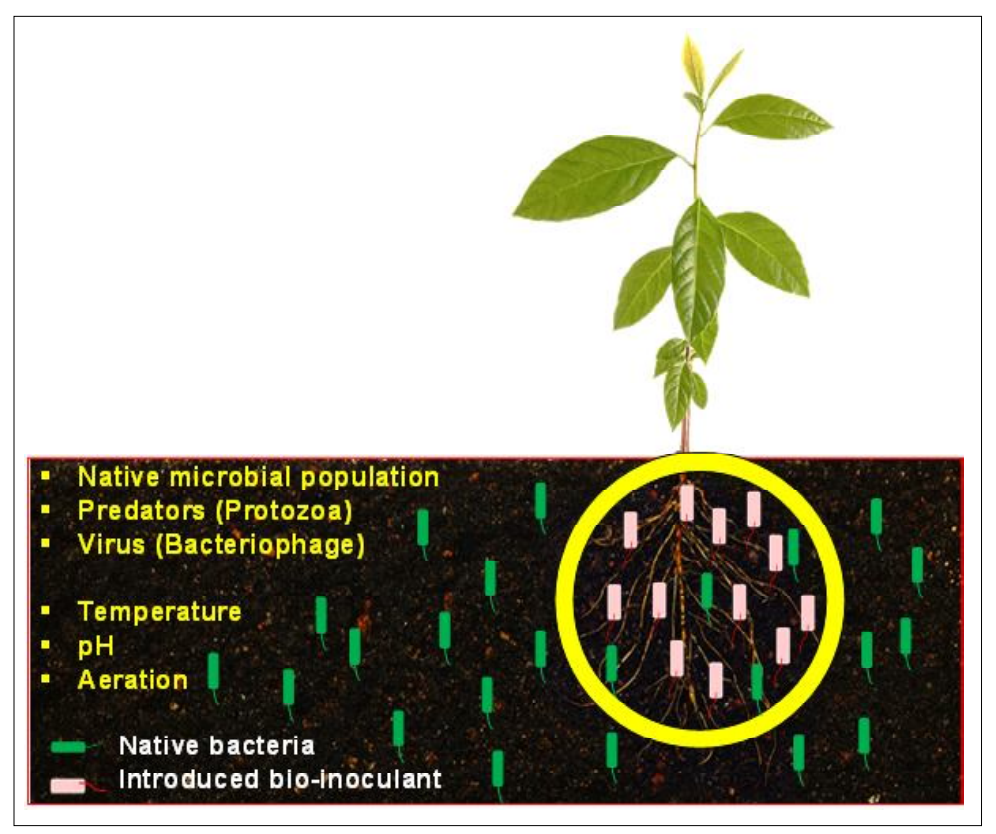

Fig 1: The effects of biotic and abiotic stress on bio-inoculant survival in soil 
Constrains in Biofertilizer Development and Environmental Factors Influencing its Survival in Soil: A Review

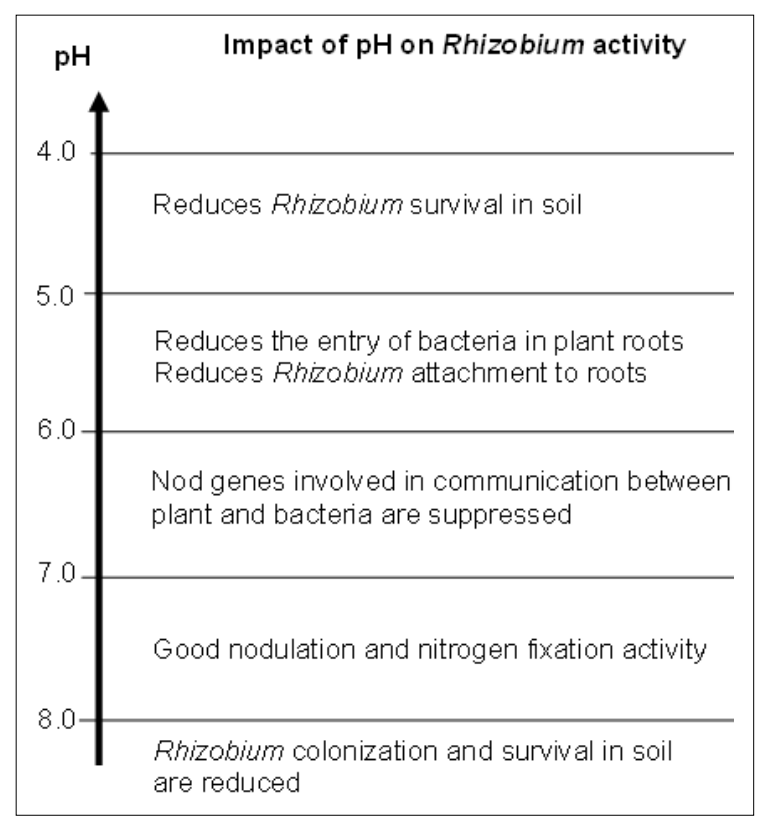

Fig 2: The effect of soil pH on the establishment of Rhizobium legume symbiosis and nitrogen fixing.

inoculants. Many of the chemical pesticides used in agriculture have a direct effect on the bio-inoculants that have been introduced. It primarily influences the survival of bio-inoculants, nodulation efficiency, nitrogen fixation, mineral solubilization and the synthesis of plant growth hormones, among other things.

\section{Native microbial population}

When biofertilizer strains are introduced to the soil, they compete with the soil's natural microbes. On the other hand, ecological interactions between soil native and introduced microorganisms are still unknown. Strains expressing features that aid the colonisation process, as well as the "fight" for the roots' environment, must be chosen to assure the efficacy of any biofertilizer (Malusà et al., 2016). The release of quorum sensing molecules, the development of biofilm and swarming movement all help bio-inoculants colonise roots more effectively. Bio-inoculants should be used in big quantities to achieve a favourable effect. In addition, the imported bio-inoculant must compete with the soil's native microflora or form a mutualistic relationship with it. Introduced microorganisms may interact with native soil organisms in a beneficial or negative way (Chapin et al., 2002; Mosupiemang et al., 2021). When Pseudomonas corrugate was used as a bio-inoculant, a positive interaction was seen in the maize rhizosphere (Kumar et al., 2007). Contrary to popular belief, Conn and Franco, (2004) found that an applied bio-inoculant suppressed numerous native soil microorganisms.

\section{Predatory organism}

Protozoan grazing, especially that of naked amoeba, the most common bacterial grazer in soil, appears to play a role in biofertilizer efficiency. Protozoans feed on specific bacterial strains in the soil (Rosenberg, 2008). Three nematode species (Caenorhabditis elegans, Acrobeloides thornei and Cruznema sp.) dramatically reduced Pseudomonas species and Bacillus subtilis colonisation in the wheat rhizosphere (Knox et al., 2003). One of the predatory bacteria against gram negative cells has been identified as Bdellovibrio naceae (Morgan et al., 2010). In addition, soil fungus and bacteria are preyed upon by Myxobacteria present in terrestrial soil (Dawid, 2000). To attack prey cells, Myxococcus xanthus uses chemotaxislike genes and predation is successful when it comes into intimate contact with pray cells (Berleman et al., 2008).

\section{Issues related to microbial strain development}

Bio-inoculants are tested and developed as a biofertilizer after being isolated from a specific crop rhizosphere region. Isolated species/strains may perform better for a single crop and have a limited host range (Vejan et al., 2016). Unlike bio-inoculants, chemical fertilisers are not crop specific and can help any crop. Bio-inoculants must also be selected to work better in a variety of crops, soil types and environmental circumstances (Meena et al., 2020). The following are some of the essential characteristics of an efficient bio-inoculant strain:

- Ability to compete with native microbial population.

- It should not antagonistic to beneficial microorganism.

- Should have higher survival rate in soil.

- Must tolerant to drought, salinity and heavy metal stress.

- Must grow in soil with low organic matter content.

- Should establish positive relationship with the host plant.

- Must express its PGP characters at maximum rate.

Table 1: Agrochemicals exhibits negative impact on introduced bio-inoculants in soil.

\begin{tabular}{|c|c|c|}
\hline Agrochemicals & Affected bio-inoculants & References \\
\hline 2,4-D & Affects the activity and nodulation of Rhizobium sp. & Fabra et al., 1997 \\
\hline $2,4,5-T$ & $\begin{array}{l}\text { Affects signalling process and establishment of symbiotic } \\
\text { relationship between legume and rhizobium }\end{array}$ & Fox et al., 2001 \\
\hline 2,4-Damine, Agroxone and Atranex & Inhibits the growth of Rhizobium sp. and Azoobacter sp. & Fabra et al., 1997 \\
\hline Glyphosate & Growth and nitrogen fixing ability of Azotobacter sp. is affected & Santos and Flores, 1955 \\
\hline Captan and Thiram & Inhibits the growth and nitrogen fixing ability of Azospirillum brasilense & Di Ciocco and Rodríguez, 1997 \\
\hline Apron, Arrest and Captan & Reduce the survivability of Rhizobium ciceri & Kyei-Boahen et al., 2001 \\
\hline Carbendazim, Imazetapir, Thiram & Reduce nitrogenase activity of nitrogen fixing bacteria & Niewiadomska, 2004 \\
\hline Carbofuran, Ethion,and Hexaconazole & Inhibits the nitrogenase activity of cyanobacteria & Kalam and Mukherjee, 2001 \\
\hline
\end{tabular}




\section{Quality control}

The Indian government has established the basic requirements for bio-inoculant production and marketing, however there is no continual monitoring of the goods on the market. The Government of India, Ministry of Agriculture and Rural Development, enforces the Fertilizer Control Order FCO (1985). Since 2006, biofertilizers and organic fertilisers have been incorporated in FCO. Quality specifications for both the carrier and the liquid biofertilizer were developed and implemented. Many requirements for production and quality control for biofertilizer manufacture have been established (Pandey and Chandra, 2016). However, India has a very small number of quality control laboratories dedicated to the bio-inoculants. It is critical to enhance the number of quality control laboratories staffed by technical personnel in order to provide farmers with high-quality bio-inoculants.

\section{Constrains in bio-inoculants production and usage}

Basu et al. (2021) review many constraints linked to bioinoculants in detail and a list of relevant constraints is provided in Fig 3. The ten major constraints in the field of bio-inoculant production and use include biological, technological, regulatory, infrastructural, financial, marketing, field-level, quality control, carrier and biosafety. Biological restrictions associated with the microbial strain and their competition with soil micro and macro flora and fauna. Because biofertilizers contain living microbial strains, product shelf life and effectiveness reduction owing to mutation are regarded as technological constraints.

New product registration takes a lengthy time and there are no uniform regulatory policies in India for biofertilizer production. Infrastructure for bio-inoculant production and quality control necessitates sophisticated technology, trained personnel and a considerable financial investment to

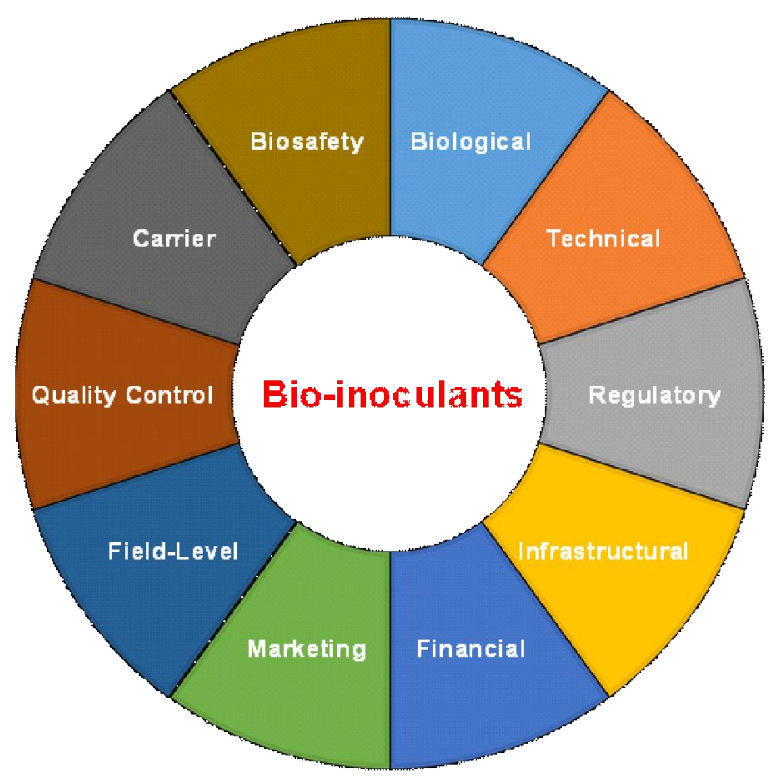

Fig 3: Various constraints involved in the development and successful application of bio-inoculants. construct a large-scale production plant. Farmers' interest in purchasing bio-inoculants is very low and a lack of information about their use creates marketing constraints. At the field level, the efficacy of bio-inoculants is not immediate, because the applied microbe must adapt to a new environment and colonise the root system before providing benefits to the plant. At field-level constraints, farmers are hesitant to use bio-inoculants because they want immediate results. Continuous availability of carrier matter is a big issue for a manufacturing company and quality testing of the product necessitates sophisticated technology that most farmers do not have access to. The biosafety of the bio-inoculants is the most significant constraint, because microorganisms evolve naturally and some mutations might lead to the development of dangerous characteristics.

\section{Future Prospects}

The lack of research into viable delivery strategies for improved soil survival of imported microbial populations is largely to blame for bio-inoculant efficiency. Farmers' use of bio-inoculants is aided by adequate and effective extension activity, agro market growth, government and private sector technical assistance participation and longterm investment. Even if it is not possible to replace chemical fertilisers entirely with bio-inoculants for plant nutrition, at least a partial substitution is required. The use of bioinoculants to partially replace chemical fertilisers is being investigated as a method of reducing pollution while preserving productivity. Rather than focusing on single microbial strains, future research should concentrate on the formation of consortia containing microorganisms that can increase plant nutrition, alleviate plant stress, mobilise plant nutrients and bio-control of important diseases.

\section{REFERENCES}

Allison, S.D., Wallenstein, M.D. and Bradford, M.A. (2010). Soil carbon response to warming dependent on microbial physiology. Nature Geoscience. 3(5): 336-340. https:// doi.org/10.1038/ngeo846.

Antoun, H. and Prevost, D. (2005). Ecology of Plant Growth Promoting Rhizobacteria. In: PGPR: Biocontrol and Biofertilization [Z.A. Siddiqui (Ed.)], Springer. (pp. 1-38).

Aruna, B. and Jain, D. (2021). Isolation, Characterization of Phosphatase Producing Bacteria and Fungi-Their Effect on Enhancing the Growth of Vigna radiate. Indian Journal of Agricultural Research. 55: 396-402.

Basu, A., Prasad, P., Das, S.N., Kalam, S., Sayyed, R. Z., Reddy, M.S. and El Enshasy, H. (2021). Plant growth promoting rhizobacteria (PGPR) as green bioinoculants: Recent developments, constraints and prospects. Sustainability. 13(3): 1140. https://doi.org/10.3390/su13031140.

Berleman, J.E., Scott, J., Chumley, T. and Kirby, J.R. (2008). Predataxis behavior in Myxococcus xanthus. Proceedings of the National Academy of Sciences of the United States of America. 105(44): 17127-17132. https:/doi.org/ 10.1073/pnas.0804387105. 
Bhardwaj, D., Ansari, M.W., Sahoo, R.K. and Tuteja, N. (2014). Biofertilizers function as key player in sustainable agriculture by improving soil fertility, plant tolerance and crop productivity. Microbial Cell Factories. 13: 66. https:/ /doi.org/10.1186/1475-2859-13-66.

Chapin, F., Matson, P.A. and Mooney, H.A. (2002). Principles of terrestriael ecosystem ecology. Springer.

Chen,L.S.,Figueredo, A., Villani, H., Michajluk, J.and Hungria, M. (2002). Diversity and symbiotic effectiveness of rhizobia isolated from field-grown soybean nodules in Paraguay. Biology and Fertility of Soils. 35(6): 448-457. https:// doi.org/10.1007/s00374-002-0493-1

Conn, V.M. and Franco, C.M.M. (2004). Effect of microbial inoculants on the indigenous actinobacterial endophyte population in the roots of wheat as determined by terminal restriction fragment length polymorphism. Applied and Environmental Microbiology. 70(11): 6407-6413. https://doi.org/10.1128/AEM.70.11.6407-6413.2004

Dawid, W. (2000). Biology and global distribution of myxobacteria in soils.FEMS Microbiology Reviews. 24(4): 403-427. https://doi.org/10.1111/j.1574-6976.2000.tb00548.x

Di Ciocco, C.A. and Rodríguez Cáceres, E. (1997). Effect of the fungicide captan on Azospirillum brasilense $\mathrm{Cd}$ in pure culture and associated with Setaria italica. Revista Argentina de Microbiología. 29(3): 152-156.

Duzan, H.M., Mabood, F., Souleimanov, A. and Smith, D.L. (2006). Nod Bj-V (C18:1, MeFuc) production by Bradyrhizobium japonicum (USDA110, 532C) at suboptimal growth temperatures. Journal of Plant Physiology.163(1):107111.https://doi.org/10.1016/j.jplph.2005.04.029.

Fabra, A., Duard, R. and Duard, A.E. (1997). de Toxicity of 2,4Dichlorophenoxyacetic Acid to Rhizobium sp in Pure cultre. Bulletin of Environment Contamination and Toxicology. 59: $645-652$

Fox, J.E., Starcevic, M., Kow, K.Y., Burow, M.E. and McLachlan, J.A. (2001). Nitrogen fixation: Endocrine disrupters and flavonoid ignalling. Nature. 413(6852): 128-129.https:// doi.org/10.1038/35093163

Graham, P.H. (1992). Stress tolerance in Rhizobium and Bradyrhizobium and nodulation under adverse soil conditions. Canadian Journal of Microbiology. 38(6): 475-484.http://doi.org/ 10.1139/m92-079

Kalam, A. and Mukherjee, A.K. (2001). Influence of hexaconazole, carbofuran and ethion on soil microflora and dehydrogenase activities in soil and intact cell. Indian Journal of Experimental Biology (IJEB). 39(1): 90-94.

Knox, O.G.G., Killham, K., Mullins, C.E. and Wilson, M.J. (2003). Nematode-enhanced colonization of the wheat rhizosphere. FEMS Microbiology Letters. 225(2): 227-233. https://doi.org/ 10.1016/S0378-1097(03)00517-2.

Kumar, B., Trivedi, P. and Pandey, A. (2007). Pseudomonas corrugata: A suitable bioinoculant for maize grown under rainfed conditions of Himalayan region. Soil Biology and Biochemistry. 39(12): 3093-3100. https://doi.org/10.1016/j.soilbio.2007. 07.003.

Kyei-Boahen, S., Slinkard, A.E. and Walley, F.L. (2001). Rhizobial survival and nodulation of chickpea as influenced by fungicide seed treatment. Canadian Journal of Microbiology. 47(6): 585-589. https://doi.org/10.1139/w01-038.
Lin, M.H., Gresshoff, P.M. and Ferguson, B.J. (2012). Systemic regulation of soybean nodulation by acidic growth conditions. Plant Physiology. 160(4): 2028-2039. https://doi.org/10.110pp. 112.204149.

Malusà, E., Pinzari, F. and Canfora, L. (2016). Efficacy of biofertilizers: Challenges to improve crop production. In D.P. Singh, H.B. Singh and R. Prabha (Eds.), Microbial inoculants in sustainable agricultural productivity (pp. 17-40). Springer.

Meena, R.S., Kumar, S., Datta, R., Lal, R., Vijayakumar, V., Brtnicky, M., Sharma, M.P., Yadav, G.S., Jhariya, M.K., Jangir, C.K., Pathan, S.I., Dokulilova, T., Pecina, V. and Marfo, T.D. (2020). Impact of agrochemicals on soil microbiota and management: A review. Land. 9(2): 34. https://doi.org/ 10.3390/land9020034.

Meena, M., Swapnil, P., Divyanshu, K., Kumar, S., Harish, Tripathi, Y.N., Zehra, A., Marwal, A. and Upadhyay, R.S. (2020). PGPR-mediated induction of systemic resistance and physiochemical alterations in plants against the pathogens: Current perspectives. Journal of Basic Microbiology. 60(10): 828-861. https://doi.org/10.1002/jobm.202000370.

Morgan, A.D., MacLean, R.C., Hillesland, K.L. and Velicer, G.J. (2010). Comparative analysis of Myxococcus predation on soil bacteria.Applied and Environmental Microbiology. 76(20): 6920-6927. https://doi.org/10.1128/AEM.00414-10

Morón, B., Soria-Díaz, M.E., Ault, J., Verroios, G., Noreen, S., RodríguezNavarro, D.N., Gil-Serrano, A., Thomas-Oates, J.,Megías, M. and Sousa, C. (2005). Low pH changes the profile of nodulation factors produced by Rhizobium tropici CIAT899. Chemistry and Biology.12(9):1029-1040.https://doi.org/ 10.1016/j.chembiol.2005.06.014

Mosupiemang, M., Bareeleng, K., Chiduwa, M.S. and Molosiwa, O.O. (2021). Stimulation of Soybean (Glycine max) Growth and Yield using Bradyrhizobium Inoculants in the Semiarid Environment of Botswana. Legume Research. (44): 1186-1191.

Niewiadomska, A. (2004). Effect of carbendazim, Imazetapir and thiram on nitrogenase activity, the number of microorganisms in soil and yield of red clover (Trifolium pratense L.). Polish Journal of Environmental Studies. 13: 4.

Pandey, V. and Chandra, K. (2016). Agriculturally important microorganisms as biofertilizers: Commercialization and regulatory requirements in Asia. In H. B. Singh, B.K. Sarma and C. Keswani (Eds.), Agriculturally important microorganisms (pp. 133-145). Springer.

Palia, M., Saravanan, S., Prasad, V.M., Upadhyay, R.G. and Kasera, S. (2021). Effect of Different Levels of Organic and Inorganic Fertilizers on Growth, Yield and Quality of Brinjal (Solanum melongena L.). Agricultural Science Digest. 41: 203-206.

Rosenberg, K. (2008). Interactions in the rhizosphere of Arabidopsis thaliana: Effects of protozoa on soil bacterial communities [Dissertation]. Technical University of Darmstadt.

Santos, A. and Flores, M. (1995). Effects of glyphosate on nitrogen fixation of free-living heterotrophic bacteria [Lett]. Letters in Applied Microbiology. 20(6): 349-352.https://doi.org/ 10.1111/j.1472-765X.1995.tb01318. 
Tudi, M., Daniel Ruan, H., Wang, L., Lyu, J., Sadler, R., Connell, D., Chu, C. and Phung, D.T. (2021). Agriculture development, pesticide application and its impact on the environment. International Journal of Environmental Research and Public Health. 18(3): 1112. https://doi.org/10.3390/ ijerph18031112.

Vejan, P., Abdullah, R., Khadiran, T., Ismail, S. and Nasrulhaq Boyce, A. (2016). Role of plant growth promoting rhizobacteria in agricultural sustainability-A review. Molecules. 21(5): 573. https://doi.org/10.3390/molecules21050573.
Wu, Y., Yu, X., Wang, H., Ding, N. and Xu, J. (2010). Does history matter? Temperature effects on soil microbial biomass andcommunity structure based on the phospholipid fatty acid (PLFA) analysis. Journal of Soils and Sediments. 10(2): 223-230. https://doi.org/10.1007/s11368-009-0118-5.

Zhang, L., Yan, C., Guo, Q., Zhang, J. and Ruiz-Menjivar, J. (2018). The impact of agricultural chemical inputs on environment: Global evidence from informetrics analysis and visualization. International Journal of Low-Carbon Technologies. 13: 338-352. https://doi.org/10.1093/ijlct/cty039. 